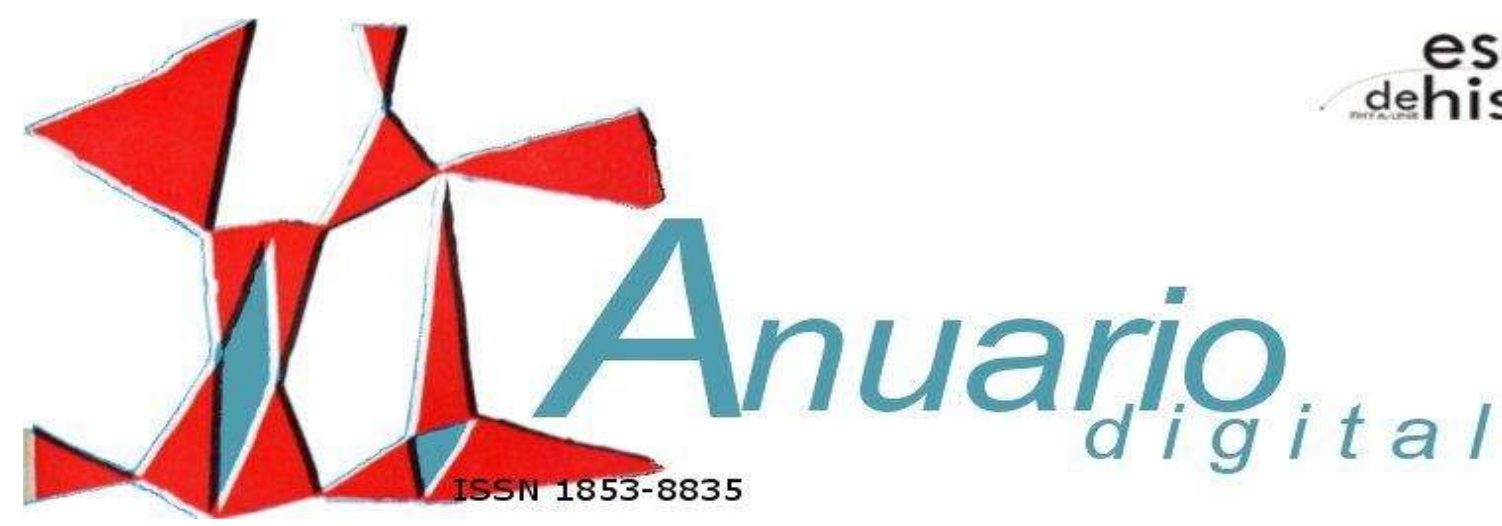

\title{
PRÁCTICAS EMPRESARIALES Y CONFLICTIVIDAD OBRERA. EL CASO DE UN ASTILLERO ESTATAL, ASTILLERO RÍO SANTIAGO (1973-1976)
}

IVONNE BARRAGÁN*

(Universidad de Buenos Aires - FLACSO); ivobarragan@yahoo.com.ar

\section{RESUMEN}

Este artículo propone abordar, a partir de la mirada situada en un estudio de caso, dos procesos sociales complejos en su interrelación en el trienio 1974-1976. La profundización de la organización y movilización de base de los trabajadores del Astillero Río Santiago de forma análoga al conjunto de prácticas y acciones empresariales desarrolladas por la dirección militar del astillero en torno a la noción de desarrollo de una modalidad de paternalismo autoritario que implicó en el período el despliegue de medidas disciplinadoras, coercitivas y represivas sobre la fuerza de trabajo de manera de asegurar la recomposición hegemónica del orden militar en la fábrica en el período previo al Golpe de Estado de 1976.

Palabras clave: disciplinamiento - beneficios - paternalismo - violencia

\footnotetext{
* Lic. en Historia UNMdP, Becaria Doctoral de la Universidad Nacional de Buenos Aires (UBA), proyecto de investigación “Organización y prácticas de lucha obrera y sus vinculaciones con las políticas laborales en el Astillero Río Santiago (1964-1984)", con sede en el Instituto de Investigaciones Gino Germani de la Facultad de Ciencias Sociales, donde integra el proyecto UBACyT "Lógicas militantes, lógicas militares y formas del recuerdo. Lo político y la política en las décadas de 1960 y 1970" (2011-2014). Investigadora del Programa Estudios del trabajo, movimiento sindical y organización industrial AEyT de la Facultad Latinoamericana de Ciencias Sociales (FLACSO).
} 
ABSTRACT

Business practices and labour unrest. The case of a state shipyard Astillero Río Santiago (1973-1976)

This paper aims to analyze the complex relationship between two social processes in 1974-1976. We address the process of grassroots organization and mobilization at the Rio Santiago Shipyard (Astillero Río Santiago) in dialogue with those management actions and practices that can be defined as a sort of authoritarian paternalism. It is our hypothesis that the display of disciplinary, coactive and repressive measures over the workforce pursued the hegemonic recomposition of the military order in the factory prior to the 1976 Coup d'Etat.

Key words: disciplining - profit - paternalism - violence

\section{Introducción}

Los estudios de la clase trabajadora que proponen una mirada relacional con la historia de las empresas han producido en los últimos años aportes relevantes en la historiografía local. Esta perspectiva contribuye a superar divisiones disciplinarias tradicionales y a construir aproximaciones complejas sobre la naturaleza de la acción y la conflictividad obrera en contextos situados.

Este trabajo es un avance de investigación que propone analizar la construcción de un tipo de relaciones laborales desde la perspectiva de caso a partir de indagar desde una perspectiva relacional las prácticas empresariales y las formas de organización y lucha colectiva de los trabajadores. El Astillero Río Santiago (ARS), situado en la localidad de Ensenada, durante el proceso de industrialización por sustitución de importaciones (ISI) llegó a constituirse en el astillero más importante de América Latina. Para este abordaje se planteó un recorte temporal específico desarrollado entre los años 1973 y 1976. Dicho recorte estuvo definido políticamente por la temporalidad del tercer gobierno peronista a nivel nacional; económicamente por la vigencia del Pacto Social; en términos sociales, por la intensificación del proceso de lucha de clases y, en términos específicos del caso, por la coexistencia de una estrategia empresarial de

\section{6}

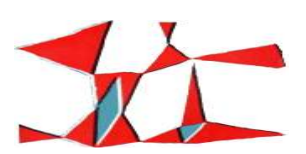

Anuario № 25, Escuela de Historia

Revista Digital № 4, Facultad de Humanidades y Artes, Universidad Nacional de Rosario, 2013

ISSN 1853-8835 
incremento de la productividad laboral y racionalización productiva; y un crecimiento cualitativo y cuantitativo de la organización de base de sus trabajadores. ${ }^{1}$

La mirada sobre la fisonomía y características de los planteos empresariales ante el desarrollo de la conflictividad obrera nos permitió identificar un proceso simultáneo y contradictorio en tanto promovieron una relación contractual de "privilegio" y "beneficio relativo" y desplegaron crecientes acciones de violencia, coerción y represión sobre la fuerza de trabajo.

Nuestro abordaje de las relaciones capital-trabajo en la fábrica -donde la singularidad radica en que se trata de una empresa de capitales estatales-, parte del concepto que plantea que todo ordenamiento productivo requiere de un grado constitutivo de violencia en simultaneidad a la construcción de cooperación que se despliegan de forma dialéctica sobre la fuerza de trabajo en su conjunto y sobre el cuerpo del trabajador individual. ${ }^{2}$ Las acciones del directorio de esta fábrica tendieron a ordenar las relaciones de producción a partir de la implementación de un conjunto de medidas complementarias a las nociones de control y vigilancia y configuraron un universo de beneficios relativos para los trabajadores a fin de lograr el mayor grado de colaboración y apropiación de los intereses de la empresa. Sin embargo, ante la profundización del ciclo de conflicto obrero a partir del año 1973, se asistió a la eclosión de aquella dinámica. $^{3}$

En una primera parte de este artículo reconstruiremos las características distintivas del Astillero a partir de una aproximación al sujeto empleador y de las relaciones laborales que este configuró. En segundo término, abordaremos la trayectoria de organización obrera en la planta para, finalmente, interrogarnos sobre el desarrollo de prácticas empresariales de integración y disciplinamiento hacia la fuerza de trabajo correlativamente al desarrollo de la conflictividad obrera.

\footnotetext{
${ }^{1}$ El llamado Pacto social promovido por el tercer gobierno peronista fue firmado el 8 de junio de 1973 por la conducción de la central obrera Confederación General del Trabajo (CGT) y la central empresaria Confederación General Económica (CGE) tendiente a clausurar los aumentos de precios en los artículos de consumo masivo y las discusiones salariales por el término de dos años.

2 Sobre estos temas quienes marcaron el campo principal de aportes teóricos que nutren nuestra perspectiva: Marx, Carlos; El capital; T. I; V. II.; Siglo XXI; Argentina; 2011; pp. 391-408 y Foucault, Michel; Vigilar y castigar; Siglo XXI; México; 1976; pp. 139-174.

${ }^{3}$ Una primera aproximación a esta problemática se realizó desde una perspectiva comparativa entre las acciones empresariales de una empresa pública como el ARS y una industria privada. Ver Barragán, Ivonne y Rodríguez, Florencia; "Estrategias patronales y conflictividad obrera en grandes industrias dinámicas. Una mirada comparativa sobre los casos Propulsora Siderúrgica (PPS) y Astillero Río Santiago (ARS) de la región de Ensenada entre 1973 y 1975"; ponencia presentada en VII Jornadas de Sociología de la Universidad Nacional de La Plata. "Argentina en el escenario latinoamericano actual: debates desde las ciencias sociales"; Diciembre de 2012; ISSN 2250-8465.
}

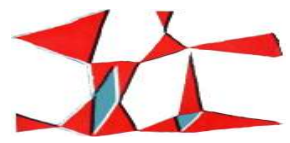

Anuario № 25, Escuela de Historia Revista Digital № 4, Facultad de Humanidades y Artes, Universidad Nacional de Rosario, 2013 ISSN 1853-8835 


\section{El Astillero Río Santiago: la patronal militar y la gestión del trabajo}

El ARS tuvo sus orígenes en 1933 en los talleres navales de la Base Naval Militar de Río Santiago, ubicado al margen del río del mismo nombre, comenzó a funcionar como astillero en 1953 y junto con la Fabrica Naval de Explosivos de Azul (FANAZUL) integraron Astilleros y Fábricas Navales del Estado (AFNE). ${ }^{4}$ Su directorio se conformó por militares pertenecientes a la Fuerza Naval y tuvo como fundamento la necesidad de cumplimentar el abastecimiento de armamentos y material para el funcionamiento de las Fuerzas Armadas con producción local. ${ }^{5}$ En el año 1969 la empresa modificó su forma societaria y se constituyó como Sociedad Anónima del Estado con mayoría accionaria en poder del Ministerio de Defensa, finalmente, en 1976, el paquete accionario mayoritario pasó al Comando en Jefe de la Armada.

El astillero producía y reparaba unidades navales, civiles y militares y durante la última fase del proceso de industrialización sustitutiva (1964-1974) consolidó una diversificada producción de bienes de capital e insumos para industrias dinámicas. La producción del ARS estaba orientada al abastecimiento del mercado interno, construía buques para la marina mercante y para la armada nacional. En esta etapa parte de su producción se destinó a otros sectores de la economía, como bienes de capital durables. El Estado cumplió un rol protagónico en esta empresa ya que la dinámica productiva específica requirió de inversión, financiamiento, planificación y tiempos de fabricación relativamente prolongados dado que la producción no era seriada sino por encargo. ${ }^{6}$ En la rama metalmecánica desarrolló insumos para las siguientes industrias: grandes motores eléctricos, tanques de envase; elementos y maquinarias para la actividad ferroviaria; compuertas para diques; equipos de bombeo para la industria petrolera; fundición de aceros,

\footnotetext{
${ }^{4}$ Decreto del Poder Ejecutivo Nacional (PEN) № 10.627 del 15 de junio de 1953.

${ }^{5}$ Entre los años 1935 y 1947 el Estado argentino creó los siguientes establecimientos productivos vinculados estratégicamente a las fuerzas armadas: 1935 Fabricaciones Militares (FM), producción de Aceros Lingotes y Laminados; 1936 FM, fábrica de Armas Portátiles "Domingo Matheu"; 1936, FM Río Tercero, producción de Ácido nítrico, ácido sulfúrico, óleum, fundición, forja mediana y pesada, tornería pesada y de precisión; 1937 FM fabricación de Pólvoras y Explosivos en la fábrica Villa María Explosivos de uso civil y sismográfico, nitrocelulosa, gelinita, dinamita, éter, pólvora; 1942, FM Cartuchos San Francisco destinada a la producción de Cartuchos Discos para agricultura; 1943, Altos Hornos Zapla (Arrabio); 1944, FM de Vainas y Conductores Eléctricos (Productos no ferrosos conductores eléctricos); 1945, FM Derivados del plomo (Polvo verde, litargirio, etc.); 1945 FM Tolueno Sintético (Tolueno, benceno, productos aromáticos); 1945 FM Materiales Pirotécnicos (Accesorios de explosivos); 1947 FM Materiales de Comunicaciones y equipos (Equipos de comunicaciones y eléctricos y material y equipo de dotación para la tropa). Ver Panaia, Marta; Lesser, R. y Skupch, Pedro; Estudios sobre los orígenes del peronismo; Siglo XXI; Buenos Aires; 1973.

${ }^{6}$ Síntesis de la Economía Real № 51; Centro de Estudios para la Producción, SEPYME; Ministerio de Economía; Marzo 2006. Disponible en: http://www.cep.gov.ar/descargas new/sintesis economia real/2006/p51 sintesis.pdf
}

298

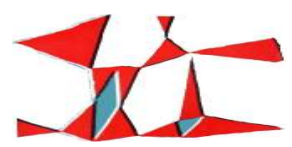

Anuario № 25, Escuela de Historia

Revista Digital № 4, Facultad de Humanidades y Artes, Universidad Nacional de Rosario, 2013 ISSN 1853-8835 
hierros y metales; maquinaria para las industria del azúcar y del papel y la construcción de turbinas hidráulicas para centrales hidroeléctricas. ${ }^{7}$

La modalidad de inscripción laboral en esta fábrica se caracterizó, en términos generales, por ingresos salariales comparativamente altos en relación con otras fábricas de la región; la existencia de posibilidades de movilidad, ascenso y promoción laboral; formación técnica; estabilidad y otra serie de beneficios como guarderías para los hijos de los trabajadores y cláusulas de ajuste del salario de bolsillo atadas al aumento del transporte. Estas condiciones beneficiosas en que se inscribía la fuerza de trabajo, en este período, fueron institucionalizadas paulatinamente por la organización sindical mediante la negociación de tres convenios colectivos a partir del año $1971 .^{8}$

Como consecuencia de aquellos elementos, se consolidó un sistema de mercado interno de trabajo (MIT). Este caso, se inscribió en las líneas generales que compartían las grandes empresas industriales que por sus características productivas demandaban una fuerza de trabajo estable, con una formación técnica específica vinculada a la propia empresa en confluencia con la necesidad de cierto grado de identidad o lealtad de los operarios con la empresa. ${ }^{9}$

Un elemento en la estrategia de construcción de disciplina industrial fue el recurso a la profundización de la diferenciación interna al cuerpo de operarios que en el astillero parecía reificar la idea del obrero mejor pago, con beneficios relativos a su calificación y antigüedad e individualidad, tendiente a reforzar la distancia entre diferentes estamentos de obreros del ARS y entre éstos y los trabajadores empleados en ramas menos dinámicas de la región. Otra herramienta de fortalecimiento de la identificación

\footnotetext{
${ }^{7}$ Caffaso, María Elena; Astillero Río Santiago; Provincia de Buenos Aires; AFNE; 2004.

${ }^{8}$ Fondo Documental Ministerio de Trabajo y Seguridad Social (MTySS), Dirección Nacional de Relaciones de Trabajo (DNRT), fondo Convenios Colectivos de Trabajo por actividad (CCTa). En adelante MTySS DNRT CCTa. Convenio Colectivo de Trabajo entre Astilleros y Fábricas Navales del Estado S. A. y la Asociación Trabajadores del Estado N 178/1971, N²4/1973 y N 91/1975.

${ }^{9}$ Sobre la constitución de mercados internos de trabajo ver el clásico aporte de Burawoy, Michael; El consentimiento en la producción. Los cambios del proceso productivo en el capitalismo monopolista; Ministerio de Trabajo y Seguridad Social; Madrid; 1989. Para el caso del ARS Juliana Frassa pone en relevancia el rol de las trayectorias sindicales particulares en la comprensión de procesos de carácter global del mercado de trabajo y estructura económica. Hemos abordado el caso aquí tratado en diálogo con lo que la autora indaga para el contexto de precarización laboral de la década de 1990. Ver Frassa, Juliana; "Mercados internos de trabajo y relaciones laborales. La gestión del trabajo en una empresa estatal argentina en contextos de precarización"; en Revista GTP Gestión de las personas y tecnologías; no 7; Universidad de Santiago de Chile; Mayo de 2010. Disponible en formato digital en: http://www.revistagpt.usach.cl/sites/revistagpt.usach.cl/files/paginas/gpt07.pdf
}

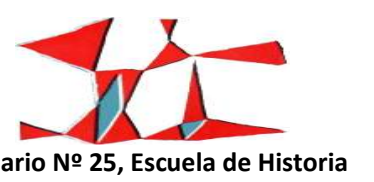

Revista Digital № 4, Facultad de Humanidades y Artes, Universidad Nacional de Rosario, 2013 ISSN 1853-8835 
de los trabajadores con el astillero fue aquella que instrumentó instancias de ingreso de los hijos o familiares de los trabajadores a la empresa ante la jubilación o un accidente de trabajo. ${ }^{10}$

Una de las modalidades más relevantes de promoción de identidad obrera fue la idea que vinculó el trabajo en el astillero con una noción de participación en la construcción de la nación desplegada desde la dirección de la fábrica. Los hallazgos de nuestro estudio para los años '70 coinciden y dialogan con lo que Juliana Frassa señala en su estudio sobre la resistencia obrera en la década de 1990. La ideología patronal configuró una estrategia de largo plazo en la configuración de las identidades de los términos de la relación laboral:

La dirección del astillero promovió entre sus trabajadores un sentimiento fuertemente nacionalista sustentado en el carácter público de la empresa y en su función de afianzar el desarrollo industrial del país. El impulso de este discurso a través de los años, sumado a los beneficios materiales y la estabilidad laboral que proveyó tradicionalmente el astillero, forjaron en los trabajadores una fuerte identidad sociolaboral relacionada íntimamente a la empresa. ${ }^{11}$

La construcción de una fuerte identificación de los trabajadores con la empresa a partir de un discurso de apelación nacionalista por la patronal militar sumada a una relación laboral beneficiosa en términos comparativos puede interpretarse como una modalidad del paternalismo industrial con rasgos peculiares. Laura Badaloni conceptualizó el paternalismo a partir de la identificación de sus componentes en términos de empresario benefactor -elemento integrador- y el componente de control y vigilancia. Es decir, esta conceptualización permite visibilizar aquellas prácticas empresarias que optaron por alternativas al puro control y que generalmente operaron como un conjunto de beneficios que se extendieron al ámbito de reproducción de la fuerza de trabajo dirigidas, fundamentalmente, a legitimar la estructura disciplinadora. De manera de abordar la construcción disciplinar a partir de su confluencia con un conjunto de beneficios laborales sin sustituirla: "por el contrario, creemos que represión y consenso son elementos

\footnotetext{
${ }^{10}$ En el tratamiento de vacantes de ingreso a la fábrica en la negociación paritaria se indica la siguiente prioridad "trabajador de la Base Naval Río Santiago, esposas e hijos de trabajadores fallecidos y/o en actividad, enviados por el gremio". MTySS DNRT CCTa. Convenio 178/1971 Asociación Trabajadores del Estado e/Astilleros y Fabricas Navales del Estado.

${ }^{11}$ Frassa, Juliana; Muñiz-Terra, Leticia y Naclerio, Alejandro; "Trayectorias empresariales divergentes frente a contextos de privatización. Un estudio comparativo de dos empresas públicas argentinas"; en Revista Economía, Sociedad y Territorio; V. X; no 32; El Colegio Mexiquense; México; enero-abril 2010; pp. 193.

Disponible en formato digital en: http://redalyc.uaemex.mx/src/inicio/ArtPdfRed.jsp?iCve=11112509007
}

300

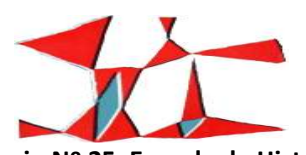

Anuario № 25, Escuela de Historia

Revista Digital № 4, Facultad de Humanidades y Artes, Universidad Nacional de Rosario, 2013 ISSN 1853-8835 
constitutivos del paternalismo que busca moldear un tipo especial de trabajador: fuerte y eficaz en el trabajo; débil y obediente frente a los patrones". ${ }^{12}$ El universo de beneficios que caracterizaron la relación contractual y las modalidades relacionales configuradas en este caso -empleador estatal y autoridad militar en el lugar de trabajo- propusieron un discurso de identificación nacional que operó sobre las condiciones de posibilidad de consolidación del poder relativo de la fracción de clase allí empleada en clave de dos variables: posición en la producción y alto salario.

Sintéticamente, podemos señalar que la fisonomía del caso radica en que la autoridad que gerenciaba este astillero propició una organización interna jerarquizada y burocrática con énfasis en modalidades de autoridad militar y a una apelación explícita a los intereses empresariales como idénticos al crecimiento nacional y al beneficio obrero. De este modo, el Astillero Río Santiago se definió como espacio fabril "privilegiado en términos contractuales", en suma a la singularidad de constituir una relación laboral caracterizada por la cotidianeidad y permanencia en la disposición al uso de la violencia. Las formas que asumió la violencia perpetrada por la patronal-militar de esta fábrica configuraron un tipo de relación social de producción e intervinieron en la consolidación de modalidades de acción sobre los cuerpos de los trabajadores.

La organización del trabajo, la relación con la patronal, las relaciones políticas al interior de la fracción de clase allí empleada y la relación entre el trabajador y sus herramientas estuvieron marcadas por una dinámica de violencia de implicancias y anclajes colectivos. Al mismo tiempo, en el plano individual, los cuerpos de los trabajadores fueron el ámbito donde confluyeron procesos contradictorios y lugar de acción del riesgo y la violencia en distintas modalidades. ${ }^{13}$ Recomponer las características y acciones distintivas de la patronal sobre los trabajadores constituye un punto de partida relevante en el estudio de la conflictividad de clase.

\footnotetext{
${ }^{12}$ Badaloni, Laura; "La familia ferroviaria a principios del siglo XX. Bienestar y lealtades de hierro en el Ferrocarril Central Argentino"; en Dicósimo, Daniel y Simonassi, Silvia (Comp.); Trabajadores y empresarios en la Argentina del siglo XX: indagaciones desde la historia social; Prohistoria; Rosario; 2011; p. 146.

${ }^{13} \mathrm{El}$ desarrollo de modalidades diferenciadas de violencia material y simbólica y sus implicancias sobre los cuerpos de los trabajadores fueron abordadas previamente. Ver Barragán, Ivonne; "Disciplinamiento industrial, represión y conflictividad obrera en una empresa estatal. Astillero Río Santiago (1973-1976)"; ponencia presentada en VI Jornadas de Historia del Trabajo y II Seminario Internacional Mundos del Trabajo del GT Mundos del Trabajo de la ANPUH; Río de Janeiro; noviembre de 2012.
}

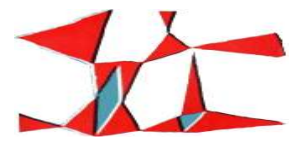

Anuario № 25, Escuela de Historia 


\section{La organización de base. Proceso de intensificación del ciclo de acción y lucha 1973-1976}

Hacia 1960 la patronal propició un modelo de demanda de fuerza laboral definido por su inscripción en el segmento calificado del mercado de trabajo que comprendía a obreros fuertes, con destreza física, capacitación técnica, pericia para el manejo de las herramientas y casi excluyentemente varones. En ese momento, el astillero empleaba aproximadamente cinco mil operarios de planta permanente y tres mil empleados de empresas contratistas destinados a distintas áreas productivas. ${ }^{14}$ La actividad industrial naval requirió de mano de obra especializada: torneros, caldereros, soldadores, mecánicos, carpinteros, electricistas, etc.; oficios considerados de largo plazo en su formación y que su dominio se lograba en la materialidad del proceso de trabajo. Como indicamos anteriormente, la empresa jugaba un rol determinante en este punto, el obrero se formaba en el taller como aprendiz bajo la guía de oficiales o a partir de su ingreso a la Escuela de Aprendices de fábrica que comenzó a funcionar el 30 de Junio de $1953 .{ }^{15}$ El lugar central del trabajo calificado de oficio en el proceso productivo en la rama naval parecía habilitar en el trabajador cualificado un importante margen de control informal en la producción y constituir un reservorio de autonomía en el desempeño de las tareas productivas. ${ }^{16}$

La zona de Ensenada, Berisso y La Plata fue una región de industrialización temprana que en este período presentaba una importante cantidad de establecimientos fabriles, con un significativo grado de sindicalización y organización de sus trabajadores, presencia de juntas y comisiones internas de fábrica que contenían tanto posturas reivindicativas tradicionales del sindicalismo industrial como ideas políticas de izquierda y movimientos de impugnación de las conducciones gremiales burocráticas. ${ }^{17}$ Los trabajadores del

\footnotetext{
${ }^{14}$ Ver Gobierno de la Provincia de Buenos Aires, sitio oficial http://www.astillero.gba.gov.ar/Historia

${ }^{15}$ La Escuela Técnica "Astillero Río Santiago" es una escuela de educación técnica privada de fábrica, reconocida por la Dirección General de Cultura y Educación de la Provincia de Buenos Aires en la actualidad, su objetivo fundamental es "formar recursos humanos para la Industria Naval". Ver http://www.astillero.gba.gov.ar/ETARS.swf

Para un análisis de las funciones de las escuelas privadas de fábrica durante la ISI ver: Rodríguez, Florencia; "Escuelas privadas de Empresa. Notas iniciales sobre una estrategia del capital en las décadas del 60 y 70"; en Elisalde, Roberto y Ampudia, Marina (comps.); Trabajadores y educación; Buenos Libros; Buenos Aires; 2010.

${ }^{16}$ El sistema de oficios en la organización de una unidad productiva puede ser entendido como "una forma de organización del trabajo caracterizada por un recorte flexible de las tareas entre individuos dotados de una gran autonomía en la preparación y ejecución de su trabajo" (François Vatin); citado en Frassa, Juliana; Muñiz-Terra, Leticia y Naclerio, Alejandro; Trayectorias empresariales divergentes; Asociación Trabajo y Sociedad-CEIL-CONICET; Buenos Aires; 2004; p. 13.

17 Una referencia clásica para abordar el la organización de los trabajadores en el período: James, Daniel; Resistencia e integración. El peronismo y la clase trabajadora argentina, 1946-1976; Siglo XXI; Buenos Aires; 2006. Para analizar el surgimiento de las corrientes sindicales denominadas combativas: Schneider, Alejandro; Los compañeros. Trabajadores, Izquierda y peronismo 1955-
} 302

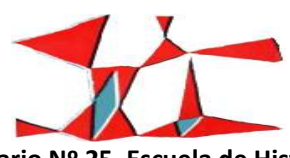

Anuario № 25, Escuela de Historia Revista Digital № 4, Facultad de Humanidades y Artes, Universidad Nacional de Rosario, 2013 ISSN 1853-8835 
astillero, agremiados en la Asociación Trabajadores del Estado (ATE), se organizaron en un amplio arco de agrupaciones políticas. La representación gremial seccional se encontró en manos del llamado peronismo ortodoxo a lo largo del período propuesto. Paralelamente, en la representación de base, avanzaron en términos representativos corrientes vinculadas a la izquierda tanto peronista como marxista.

El crecimiento de representaciones de oposición a la burocracia sindical se inscribió en el ciclo de ascenso de los conflictos de clase que se inició en 1969. Específicamente, fue durante el contexto de intensificación de las luchas sociales entre 1973 y 1975 donde los trabajadores del ARS profundizaron su proceso de organización y se generaron condiciones de posibilidad para que ciertos ordenamientos y relaciones de fuerza en el interior de la planta fueran cuestionados. La diversidad de agrupaciones representaba un completo abanico de opciones ideológicas y de acción gremial dentro de la fábrica. Cada una de ellas representó un alineamiento partidario, una política gremial reivindicativa en el astillero y un posicionamiento frente a las conducciones sindicales locales y nacionales.

En la fábrica activaban políticamente un amplio número de trabajadores en diferentes agrupaciones de base. En clave de la acción sindical, el activismo se nucleó en torno de las listas electorales, que funcionaron como receptoras y marco de diversas orientaciones políticas, algunas hegemónicas en la dirección y otras subordinadas, que de todos modos incidían parcialmente en la definición de la líneas de acción y la dinámica interna de la fábrica. Entre las más renombradas dentro de la fábrica podemos identificar la lista Azul y Blanca, vinculada a la derecha peronista, liderada por el dirigente sindical y Vice Gobernador de la Provincia de Buenos Aires Victorio Calabró; la lista Gris, que era un desprendimiento de la primera a partir de planteos pluralistas y se encontraba ligada a un sector de la izquierda peronista representada por el Gobernador de la Provincia Oscar Bidegain durante el gobierno de Héctor Cámpora; la lista Celeste, de la agrupación sindical de base Juventud Trabajadora Peronista (JTP) de la organización Montoneros y la lista Marrón que respondía al Partido Socialista de los Trabajadores, entre otras. ${ }^{18}$

1973; Imago Mundi; Buenos Aires; 2005 y Werner, Ruth y Aguirre, Facundo; Insurgencia obrera en la Argentina, $1969-1976$. Clasismo, coordinadoras interfabriles y estrategias de la izquierda; IPS; Buenos Aires; 2007; entre otros.

${ }^{18}$ Montes, José; Astillero Río Santiago. Su historia y lucha relatada por sus trabajadores; La verdad obrera; Buenos Aires; $1999 ; \mathrm{p}$. 48.

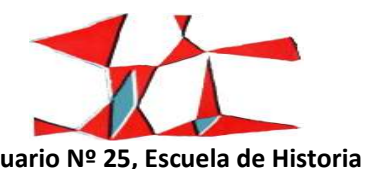


El incremento en la participación colectiva conducida por representantes de líneas opositoras a la burocracia se vio profundizado a partir de 1973 y resultó en la ampliación de los márgenes de libertad y democracia sindical al interior del astillero. ${ }^{19}$

En la estructura sindical al interior de la fábrica los delegados por sección desarrollaron importantes funciones en la discusión de los convenios colectivos - preparitarias- y de las condiciones de producción y trabajo. La elección y el desempeño de estos delegados contuvieron el conjunto de las contradicciones y enfrentamientos entre las distintas facciones en disputa al interior de la clase trabajadora en el período. ${ }^{20}$ En el marco de las luchas contra el Pacto Social el proceso de combatividad creciente desde las bases a nivel nacional se canalizó en la conformación de nuevas formas de organización colectiva como fueron las Coordinadoras Interfabriles que nuclearon a delegados y comisiones internas regionales; en este marco, sectores obreros del ARS confluyeron con la vanguardia del proceso en el territorio industrial de La Plata, Berisso y Ensenada. ${ }^{21}$

Este proceso de creciente organización sindical tuvo como marco la profundización de la lógica de violencia persistente en la fábrica y configuró las modalidades de disputa y confrontación entre las distintas facciones políticas entre los obreros y un proceso de comunión en la persecución de los nuevos representantes de la patronal militar y los sectores burocráticos del sindicalismo. Muchos de los delegados por sección electos a partir del año 1973, que pertenecían a las líneas combativas, fueron agredidos por militantes de la agrupación sindical Azul y Blanca y, posteriormente, suspendidos por las autoridades del astillero. Las facciones más violentas del sindicalismo burocrático propiciaron limitar la ascendencia de los nuevos representantes y contener el avance de la combatividad en el lugar de trabajo, en este sentido, la violencia implementada se ejerció de forma ejemplificadora. La resolución a los golpes de las asambleas fue tornándose cada vez más frecuente, las amenazas a delegados de las corrientes combativas acusándolos de

\footnotetext{
${ }^{19}$ Para una comprensión de la noción de burocracia sindical y sus especificidades ver Basualdo, Victoria; "La 'burocracia sindical': aportes clásicos y nuevas aproximaciones"; en Nuevo Topo. Revista de historia y pensamiento crítico; № 7, 2010.

${ }^{20}$ Ver, entre otros, Azpiazu, Daniel; Basualdo, Victoria y Schorr, Martín; La industria y el sindicalismo de base en la Argentina; Cara o Ceca; Buenos Aires; 2010.

${ }^{21}$ Sobre esta nueva modalidad de organización y lucha ver, entre otros, Lobbe, Héctor; La Guerrilla Fabril: Clase obrera e izquierda en la Coordinadora de Zona norte de Gran Buenos Aires (1975-1976); RyR; Buenos Aires; 2006. Colom, Yolanda y Salomone, Alicia; "Las Coordinadoras ínterfabriles de Capital Federal y Gran Buenos Aires"; en Razón y Revolución; № 4; Buenos Aires; 1997 y Rodríguez, Florencia, Slatman, Melisa, Lascano, Natalia; "Las Coordinadoras Interfabriles de Capital y Gran Buenos Aires (19751976): Un estado del arte"; en Revista Theomai. Estudios sobre Sociedad y Desarrollo; Buenos Aires; 2008.
}

304

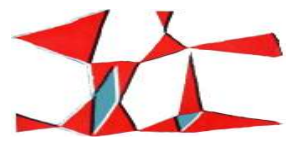

Anuario № 25, Escuela de Historia

Revista Digital № 4, Facultad de Humanidades y Artes, Universidad Nacional de Rosario, 2013 ISSN 1853-8835 
"comunistas" y la recurrencia al "apriete" por patotas marcaron crecientemente la dinámica de la acción gremial entre los operarios y militantes.

La composición de la representación de base descripta propició modalidades de acción obrera y conflicto diferenciadas. Por una parte, las acciones de lucha organizadas sindicalmente se dieron con objetivos explícitos en el plano económico, es decir, que la disputa salarial fue liderada generalmente por la representación sindical regional en manos de la Azul y Blanca. Paralelamente, las reivindicaciones por condiciones de trabajo y sus implicancias de riesgo sobre los cuerpo de los trabajadores fueron desplazadas a un conjunto de acciones más desarticuladas que, liderada por delegados de sección, se desplegaban como cotidianidad del riesgo físico y violencia inherentes a la actividad productiva en sí misma y se condensó en la repita frase entre los trabajadores "un barco, un muerto". ${ }^{22}$

Son destacables los elementos de encuentro y diálogo con la investigación del historiador Federico Lorenz sobre la organización política y sindical de base en Astilleros ASTARSA S.A. El análisis de Lorenz sobre la constitución de la violencia como herramental y cotidianeidad de la acción política de los trabajadores y representantes sindicales de base aportó nociones y elementos interpretativos a nuestro abordaje de la noción de violencia como elemento configurativo de la relación laboral en la fábrica. En términos específicos de las condiciones generales de la rama, Lorenz describe:

El trabajo naval es un conjunto de tareas especialmente duras: se trabajaba con hierros, calor, gases, fuego, a veces a varios metros de altura, y otras bajo la línea de flotación de los cascos ya botados de los barcos aún en construcción. Es peligroso y en muchos aspectos insalubre, lo que generaba un ambiente propenso a que se produjeran accidentes. El golpeteo incesante sobre metales y chapas poblaba el aire de ruidos sordos. Las emanaciones tóxicas de pinturas y material de soldadura producían afecciones pulmonares de distinto grado de complejidad... Existía entre los trabajadores el mito de que "cada barco construido se llevaba uno o dos obreros". ${ }^{23}$

\footnotetext{
${ }^{22}$ Esta expresión se repitió en una serie de testimonios y figura en la presentación realizada por la Central de Trabajadores Argentinos (CTA) ante la Cámara Federal de La Plata. Comisión por la Verdad, hacia la justica; La Plata, 22 de marzo de $2000 ;$ p. 9.

${ }^{23}$ Lorenz, Federico; Algo parecido a la felicidad. Una historia de la lucha de la clase trabajadora durante la década del setenta (19731978); Edhasa; Buenos Aires; 2013; p. 69.
}

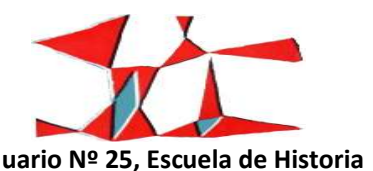


En este marco, se pudo constatar que en el caso del ARS la cotidianeidad del riesgo en el proceso de trabajo se desplegó en una dinámica de acciones individuales y/o conjuntas de solidaridad, heroísmo y compañerismo que crecientemente circunscribieron la resolución del conflicto al ámbito de la violencia física y no al de la acción sindical organizada. ${ }^{24}$

\section{Acción empresarial y acción obrera. La resolución disciplinadora del desafío planteado por el trabajo}

En el trienio analizado en este trabajo la dirección del astillero promovió un proceso de incremento de la productividad que se evidenció en el adelanto de los tiempos de entrega de los barcos - de dos años a nueve meses-. ${ }^{25}$ La racionalización impulsada por la patronal se expresó en la imposición de horarios continuos sin pagar derecho a turno, la extensión de la jornada, la creciente demanda de realización de horas extras y la profundización de un incipiente proceso de terciarización laboral que resultó en el quite de fuentes de trabajo en las secciones de cobrería, montaje y carpintería de abordo. ${ }^{26}$

En este contexto, la acción colectiva de los trabajadores del ARS sintetizó una trayectoria de organización que fue creciendo geométricamente desde 1973, a partir de la elección de cincuenta y seis delegados nuevos por sección y de la designación de representantes paritarios, que desplegaron diferentes formas de protesta, movilización y lucha. ${ }^{27}$ Las distintas acciones organizadas sindicalmente se dieron en el plano salarial, mientras que la conflictividad originada a raíz de las condiciones de trabajo y sus implicancias en el cuerpo de los trabajadores configuraron un conjunto de acciones desarticuladas y sin conducción gremial institucionalizada. En este tipo de demandas el eje giró en torno del peligro físico como rasgo propio

\footnotetext{
${ }^{24}$ En un trabajo comparativo previo se abordó esta dinámica desde una perspectiva de género, problematizando modelos de masculinidad presentes en la fábrica a fin de profundizar la comprensión de la naturaleza y la dinámica de la conflictividad obrera. Ver, Barragán, Ivonne y Rodríguez, Florencia; “Clase, género, politización y violencia. Los casos del Astillero Río Santiago y Propulsora Siderúrgica 1974-1975"; en Revista de Estudios Marítimos y Sociales; Universidad Nacional de Mar del Plata; en prensa. Próximamente disponible en: http://estudiosmaritimos.wordpress.com/

${ }^{25}$ Volante iBasta de atropello! Grupo obrero clandestino de astilleros Organización y Lucha. DIPBA: Mesa B, Carpeta 39, Legajo 43, Ensenada, Astilleros "Río Santiago", Tomo I. Informe 13 de marzo de 1971. Departamento de búsqueda.

${ }^{26}$ Un volante denunciaba: "Lo que no se dice es ¿por qué se contratan empresas privadas para trabajos que se pueden hacer en el ARS? ¿quiénes son los responsables de la falta de organización y planificación? ¿porqué faltan herramientas? ¿porqué hay laburantes sin nada de trabajo? ¿porqué no hay materiales en almacenes? ¿porqué se contrata personal superior para botonear en lugar de servir para mejorar la producción?..."; DIPBA: Mesa B, Carpeta 39, Legajo 43, Ensenada, Astilleros "Río Santiago", Tomo I. Informe 14 de agosto de 1975. Agrupación Carlos Olmedo (ARS); DIPBA: Mesa B, Carpeta 39, Legajo 43, Ensenada, Astilleros "Río Santiago", Tomo I. Informe 5 de mayo de 1971. Departamento de búsqueda.

${ }^{27}$ Presentación de la Central de Trabajadores Argentinos (CTA) ante la Cámara Federal de La Plata. Comisión por la Verdad, hacia la justicia; La Plata, 22 de marzo de 2000; p. 3.
}

306

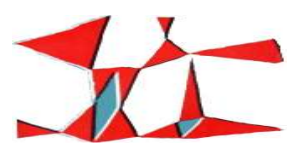

Anuario № 25, Escuela de Historia

Revista Digital № 4, Facultad de Humanidades y Artes, Universidad Nacional de Rosario, 2013 ISSN 1853-8835 
de las condiciones de trabajo en el astillero, lo que configuró un elemento normativo y normalizado de lo posible y aceptable en la lógica de riesgo de esta fábrica. La política de racionalización productiva promovida por la empresa en este período significó, en términos de riesgo físico en el proceso de trabajo, que cada barco "se estaba llevando más de un trabajador". En 1975, durante el proceso de pintura de un buque se produce un accidente en el que dos trabajadores murieron ahogados. Al fallar los frenos de la grúa flotante, cayeron al río, sin equipamiento de seguridad ni chalecos salvavidas. Uno murió ahogado luego de quedar inconsciente producto del golpe. El otro fallecido fue parte del grupo de compañeros de trabajo que se arrojaron al río en un intento por salvarles la vida. En diciembre del mismo año un soldador murió quemado en el interior de un buque. ${ }^{28}$ El testimonio de un operario del ARS, en referencia a este accidente, expresa dicha modalidad de acción desarticulada y sin conducción sindical que involucrara un reclamo formal a la patronal o una acción de carácter colectivo:

“Había una frase hecha que se repetía 'un barco, un muerto, un barco, un muerto'. En el tiempo que yo estuve fue un barco dos muertos... Nosotros sabíamos que la causa del accidente era por el mal estado de los equipos para soldar. Al otro día cuando llegamos al ARS, el compañero estaba totalmente carbonizado, pero aún vivía. Con un compañero que le decíamos Chirola, agarramos el primer equipo de soldar, lo arrastramos hasta la orilla del río y lo tiramos. Cuando nos damos vuelta vemos otros trabajadores que están haciendo lo mismo. Tiramos al agua por lo menos 15 equipos. La empresa no nos dijo nada. A la semana había equipos nuevos".

En relación a la protesta obrera la dirección de la planta, por su parte, desarrolló acciones diferenciadas para cada una de estas problemáticas planteadas tendientes a reificar estrategias de subordinación de los trabajadores al poder patronal con matices de negociación. Fueron numerosos los casos en que la gerencia sostuvo un discurso fundado en la idea que el trabajo colaborativo en el ARS confluía en la "construcción y en el bien de la patria". Planteando "reclamos" a la parte obrera" esperaban que los trabajadores prestaran "más apoyo a AFNE [Astilleros y Fábricas Navales del Estado], trabajando con

\footnotetext{
${ }^{28}$ Presentación de la Central de Trabajadores Argentinos (CTA) ante la Cámara Federal de La Plata. Comisión por la Verdad, hacia la justicia. La Plata, 22 de marzo de 2000; p. 9 y 10.
}

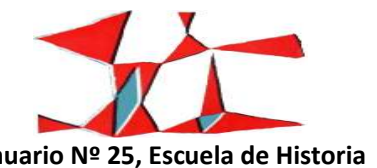


más dedicación, y buena voluntad, y en disciplina, respetando los horarios establecidos para el desayuno y almuerzo, como reciprocidad al gesto de la empresa que se muestra permeable a sus inquietudes." ${ }^{29}$

Durante este período las respuestas patronales fueron inmediatas cuando se trató de un reclamo salarial, independientemente del nivel de satisfacción que le dieran a las solicitudes de los trabajadores. En el campo delineado por la lucha económica, la patronal instrumentó una serie de recursos que consistieron en manejar los tiempos de la negociación salarial y del otorgamiento de los aumentos a partir de la posibilidad de desplazar las responsabilidades de fijación del salario a la esfera de influencia del Ministerio de Defensa o invocando los límites impuestos por la paritaria nacional. Sin embargo, en diferentes momentos, la estrategia consistió en la implementación de forma indirecta de aumentos salariales realizados, por ejemplo, bajo la forma de premios por asistencia. ${ }^{30}$ En contraposición, frente a las demandas vinculadas al proceso de producción, en especial en torno a temas del riesgo físico -donde la posibilidad de accidentes, mutilaciones y muertes pareció configurar la naturalidad de la actividad productiva en el astillero- las reacciones patronales fueron nulas o displicente.

Ante la dinámica de conflictividad obrera en el trienio 1973-1976, la patronal de la empresa implementó crecientemente un conjunto de medidas coercitivas. Se incrementaron las intervenciones y las formas de seguimiento, en una compleja trama de acciones y reacciones que profundizó el clima represivo en el espacio laboral. La violencia potencial intrínseca a su condición de autoridades militares se movió paulatinamente de un estado de latencia hacia un despliegue explícito y permanente de materialidad sobre los cuerpos de los operarios. A mediados de 1975 la dirección instaló un Infante de Marina cada tres operarios trabajando. ${ }^{31}$ La vigilancia militar en la producción permitió la visibilización y materialización de la violencia sobre los cuerpos de los operarios. Algunos testimonios dan cuenta de este clima represivo:

\footnotetext{
${ }^{29}$ DIPBA: Mesa B, Carpeta 39, Legajo 43, Ensenada, Astilleros “Río Santiago", Tomo I. Informe 27 de febrero de 1975. Departamento de búsqueda.

${ }^{30}$ A comienzos de 1975 se realizó un reclamo por aumento de emergencia. En respuesta, hacia fines del mes de febrero, el directorio propuso gestionar un premio por asistencia de treinta mil pesos $\mathrm{m} / \mathrm{n}$ en lugar de los diez mil que estaban establecidos previamente. DIPBA: Mesa B, Carpeta 39, Legajo 43 "Astillero Río Santiago de Ensenada", Tomo I, Folio 33-34, 19 de febrero de 1975.

${ }^{31}$ En la madrugada del 22 de agosto de 1975 estalló una bomba en la fragata Santísima Trinidad, aparcada para su construcción en el astillero. El atentado fue reivindicado por el Comando Arturo Lewinger de la organización Montoneros, Sin víctimas fatales esta acción generó una compleja trama de acciones y reacciones en la fábrica. Se incrementaron las intervenciones y las formas de seguimiento, se militarizó el espacio de trabajo. DIPBA: Sección “C” № 2111, Legajo 3760, "Atentado a la Fragata T-42 "Santísima 308
}

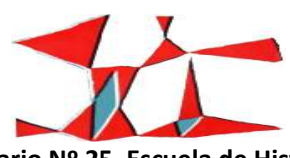

Anuario № 25, Escuela de Historia 
"los técnicos fueron a barrer, un desastre a nivel organizativo de lo que era esa organización de delegados de las fábricas. ... Porque vos un técnico del astillero, imagínate, que es como decir Favaloro, hacen buques no hacen, que se yo, chapitas, lo agarra y le dicen gracias a lo que hicieron por tirar la fragata abajo, andá a barrer el taller"132

La sistematización de la represión a cargo de las fuerzas paramilitares de la Triple A, la agudización de la violencia contra los sectores de la clase obrera más movilizados y la profundización de los enfrentamientos al interior del peronismo se materializaron a partir del fallecimiento de Perón el 1 de julio de 1974 y presentaron una línea de violencia ascendente durante 1975. Este contexto de violencia política creciente durante el desarrollo de los distintos conflictos salariales alcanzó a trabajadores y representantes de base del astillero. ${ }^{33}$ La desaparición, secuestro, tortura y asesinato de trabajadores, representantes de base y dirigentes políticos regionales estuvo dirigida explícitamente a erosionar las condiciones de posibilidad de la acción colectiva y tuvo como víctimas privilegiadas a los sectores combativos del sindicalismo en la fábrica.

Uno de hechos que condicionó de forma significativa la dinámica de conflicto en la fábrica fue aquel que, a partir de la desaparición de representantes de la burocracia -en supuesta complicidad con la dirección de la empresa-, limitó las posibilidades de aumento salarial y promovió un acuerdo posteriormente cuestionado por los trabajadores. ${ }^{34}$ Los trabajadores del astillero se movilizaron

Trinidad" amarrada en Astilleros Río Santiago 22 de Agosto de 1975", Folio 11: Comunicado refrendado por Montoneros al subdirector del Diario Clarín.

${ }^{32}$ Entrevista realizada por la autora a A.M. en 2009.

${ }^{33}$ Una solicitada de la Coordinadora de Comisiones Internas y Delegados en lucha de La Plata, Berisso y Ensenada denunciaba la ola de violencia creciente en la región, describiendo los atentados a los dirigentes sindicales: "Como ocurrió en Villa Constitución y Sierra Grande, como está ocurriendo en Córdoba y en todo el país, la ola de violencia desatada contra la clase trabajadora se acentúa en nuestra zona. Comenzó con las amenazas a los delegados De Charras y Marotte del Astillero Río Santiago; del compañero de la Comisión Directiva de AEMOPA Tamarit y los atentados contra la vivienda del delegado de Propulsora, Arturo Garín. Hoy es el macabro asesinato de los compañeros Salvador Delaturi y Juan Carlos Scaffide de Propulsora Siderúrgica S. A.; y ante esto la única respuesta oficial de la conducción de la CGT es el silencio..."; DIPBA, Mesa B, Carpeta 39, Legajo 35 "Coordinadora de Gremios-Comisiones Internas y Delegados en lucha La Plata, Berisso y Ensenada", Folio 10. Un abordaje exhaustivo de las modalidades y desarrollo histórico de la violencia política en este período en la Argentina en este período supera las posibilidades de este trabajo.

${ }^{34}$ El 29 de octubre fueron secuestrados seis operarios de planta vinculados a la lista Azul y Blanca: Carlos Lapasta, Aníbal Matracio, Nilo Bergenhau, Jorge Giménez, Juan Carlos Delleville y Néstor Toledo. DIPBA: Mesa "B", Carpeta 39, Legajo 43 Astillero Río Santiago de Ensenada, Tomo I, Diario Mayoría, 30 de octubre de 1975. Los seis trabajadores fueron liberados el 30 de Octubre de 1975 en las inmediaciones de la sede sindical de ATE Ensenada. DIPBA: Mesa B, Carpeta 39, Legajo 43 "Astillero Río Santiago de Ensenada", Tomo I, Folio 47.

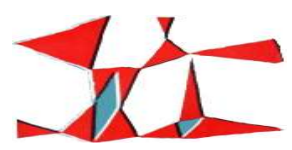

Anuario № 25, Escuela de Historia Revista Digital № 4, Facultad de Humanidades y Artes, Universidad Nacional de Rosario, 2013 ISSN 1853-8835 
masivamente en defensa de los operarios secuestrados en cada una de las ocasiones en que la violencia material se impuso sobre la dinámica sindical. ${ }^{35}$

La agudización de la violencia sistemática contra los sectores de la clase obrera más movilizados configuró condiciones de quiebre, indefensión y retroceso de las representaciones combativas que en el seno de la empresa se presentaron como un espacio de fisura que fue aprovechado por la representación sindical más conservadora y por la gerencia de distinta manera.

En este marco la patronal del astillero radicalizó su ofensiva contra los elementos más movilizados del trabajo y alteró radicalmente las condiciones para la acción colectiva de los trabajadores. Expulsó del ámbito de la fábrica, mediante un lock out, la lucha de los operarios. ${ }^{36}$ Actuó redefiniendo el lugar del enfrentamiento y recurrió a la represión de la Policía de la Provincia de Buenos Aires cuando los trabajadores intentaron realizar una asamblea en las inmediaciones de la planta. La clausura del ámbito productivo constituyó una de las acciones de mayor violencia simbólica y material hacia la fuerza de trabajo y tuvo efectos sobre su expresión colectiva e individual al provocar un significativo quiebre en la solidaridad de clase. ${ }^{37}$

\footnotetext{
${ }^{35}$ En noviembre de 1975, fueron secuestrados tres delegados de las líneas combativas. Presentación ante la Cámara Federal de La Plata, Comisión por la Verdad hacia la Justicia de la Central de Trabajadores Argentinos, marzo de 2000. El 13 de Noviembre de 1975 fue asesinado un trabajador del astillero. Mario Luis Noriega fue víctima de ejecución sumaria. Ver Informe CONADEP Nunca Más. Anexos; EUDEBA; Buenos Aires; 2006; T. II; p. 1075.

${ }^{36}$ La dirección de la empresa recurrió al cierre del establecimiento en los meses de diciembre de 1975 y marzo de 1976 como forma de clausura de las negociaciones y conflictos por el sostenimiento del nivel salarial en un marco inflacionario creciente. Diario El Día; 21 de marzo de 1976. En el matutino se publicó una solicitada firmada por la dirección de AFNE: "La medida de carácter temporal, se había adoptado en virtud de actos de indisciplina laboral y para preservar la seguridad interna del establecimiento".

${ }^{37}$ Algunos testimonios dan cuenta de las implicancias del cierre de la fábrica en el colectivo obrero: "Hoy como el viernes y el lunes los que hace años que trabajamos en este Astillero, vemos que esta situación se la debemos a la acción de los Troskos, Montos, Comunachos, a la Judía Matilde que se han pasado jodiendo con pedidos pelotudos... A ver que hacen ahora los chantas troskos, montos, comunachos y la judía Matilde, si llegan a cesantear a algunos de nosotros, compañeros, o si se llevan la Fragata y el San Antonio a Dársena Norte para terminarlos, gracias a la influencia de nuestro cornudo Ministro de Defensa que, además ya ha dicho "que para trabajar así cerramos el Astillero hasta febrero y lo depuramos de vagos y activistas", o se olvidan de 1962. Mientras tanto nosotros los que llevamos años trabajando en la empresa miramos como unos pelotudos que nos llevan como ovejas siguiendo a los chantas. Esto no va más, luchemos para que se reabra la fuente de trabajo y que se limpie tanto de abajo como de arriba de "zurdos" y corrompidos nuestro querido astillero". DIPBA: Mesa B, Carpeta 39, Legajo 43 "Astillero Río Santiago de Ensenada", Tomo I, Folio 64. Algunos volantes amenazan a los delegados combativos de ser "ajusticiados". Ídem, Folio 66.
}

310

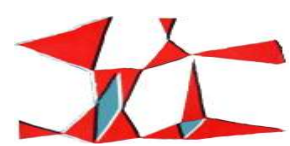

Anuario № 25, Escuela de Historia

Revista Digital № 4, Facultad de Humanidades y Artes, Universidad Nacional de Rosario, 2013 ISSN 1853-8835 
Ante la agudización de la violencia contra representantes sindicales se reunieron con el Director del Astillero a fin de solicitar su intervención y gestión en la liberación de los secuestrados. ${ }^{38}$ La respuesta de la autoridad de la fábrica fue comprometer su ayuda a cambio únicamente del levantamiento de las medidas de fuerza, recurriendo nuevamente al cierre de la empresa. ${ }^{39}$

Los secuestros y asesinatos de trabajadores del astillero sucedieron durante el desarrollo de distintos conflictos gremiales en la fábrica o convocados en solidaridad con alguna fábrica de la región; de manera que, sumada a la violencia material aplicada por la patronal militar propició la imposición de un modelo más reaccionario y tradicional en la representación sindical sobre otro emergente y subversivo. El funcionamiento represivo ejemplificatorio de las bandas ilegales, la represión a movilizaciones y protestas por las fuerzas de seguridad, la permanente presencia militar intimidatoria en la fábrica y el recurso patronal al cierre de la fuente de trabajo fueron algunas de las modalidades de la violencia material que generaron las condiciones de ruptura e indefensión en que se encontraría este colectivo obrero una vez que la acción represiva fuera implementada por el aparato estatal a partir del 24 de marzo de 1976.

\section{Palabras finales}

Las estrategias patronales frente los procesos de organización y politización de los trabajadores al interior de la fábrica configuraron las dos caras de una relación social laboral que presentó fuertes rasgos del paternalismo industrial. Parte de la acción empresarial tuvo anclaje en acciones tendientes a lograr la integración y lealtad de la fuerza de trabajo con la fábrica y con la actividad productiva que fue, a su vez, productora de elementos de identificación del trabajador con el oficio en la materialidad del proceso de trabajo.

\footnotetext{
38 Durante los días previos al 24 de marzo de 1976 los secuestros de trabajadores y hechos de violencia en la región se pronunciaron. El 19 de febrero, dos días después de recuperar la libertad tras una detención de varios meses, fue asesinado el técnico del astillero Alcides Méndez Paz. Informe CONADEP Nunca Más. Anexos; EUDEBA; Buenos Aires; 2006; T. II; p. 1064. El 19 de marzo fueron asesinados tres operarios, Fortunato Agustín Andreucci, Jorge Pedro Gutzo y José Luis Lucero, delegados e integrantes de la agrupación Celeste. Diario El Día; 21 de Marzo de 1976; p. 1.

39 DIPBA: Mesa B, Carpeta 39, Legajo 35 "Coordinadora de Gremios-Comisiones Internas y Delegados en lucha La Plata, Berisso y Ensenada", Folio 6, 19 de enero de 1976. Diario El Día; 21 de marzo de 1976. En el matutino se publicó una solicitada firmada por la dirección de AFNE: "La medida de carácter temporal, se había adoptado en virtud de actos de indisciplina laboral y para preservar la seguridad interna del establecimiento".
}

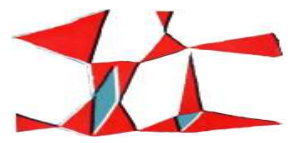

Anuario № 25, Escuela de Historia 
En este sentido, las prácticas de control y vigilancia sobre el colectivo obrero fueron "mediadas" por una serie de condiciones consideradas beneficiosas. En términos de explicitar el carácter de la relación laboral en este período, podemos sostener que la dirección militar de esta fábrica planteó un modelo con anclajes en el paternalismo industrial, fuertemente autoritario y con enérgicas apelaciones nacionalistas. ${ }^{40}$ Es decir, el conjunto de prácticas sostenidas en la gestión de la fuerza de trabajo -como un universo de beneficios productores de mitificaciones, formas manipulatorias, captura de voluntades-, en el período previo al Terrorismo de Estado, eclosionaron frente a la profundización de la protesta obrera.

El análisis de la acción patronal -estatal militar- en un contexto situado posibilitó identificar modelos de disciplinamiento de la fuerza de trabajo -que crecientemente se desplegaron en el ámbito de la violencia y, específicamente, sobre los cuerpos de los trabajadores- tendientes a lograr una recomposición hegemónica de la autoridad en el lugar de trabajo. La síntesis en términos de violencia identificada en el astillero fue la modalidad y la resolución de la disputa planteada por el trabajo y configuró la dinámica específica de la relación laboral en este período.

Recibido: 25 de marzo de 2013

Aprobado: 4 de junio de2013

Versión final: 11 de julio de 2013

\footnotetext{
${ }^{40}$ Es posible pensar el desarrollo de un tipo de paternalismo industrial de carácter coercitivo o autoritario, en términos de condicionar la generación de condiciones de empoderamiento de los trabajadores generada a partir de, por un lado, su condición estratégica en el proceso de producción y, en segundo término, de las posibilidades de superación de las elementales condiciones materiales de reproducción a partir de los altos salarios. ${ }^{40}$ Debo una primera aproximación a estas nociones al interesante aporte realizado por la Dra. Ángela Vergara (University of San Diego, California). Exposición Mesa Redonda Repensando o "trabalho" e os/as "trabalhadores/as" VI Jornadas de Historia del Trabajo y II Seminario Internacional Mundos del Trabajo del GT Mundos del Trabajo de la ANPUH; Río de Janeiro; noviembre de 2012. En referencia a la posición en la producción de estos trabajadores calificados tomamos como insumo interpretativo y en diálogo con la idea de paternalismo coercitivo la tesis del Historiador John Womack. Ver Womack, John Jr.; Posición estratégica y fuerza obrera. Hacia una nueva historia de los movimientos obreros; Fondo de Cultura Económica; México; 2007.
}

312

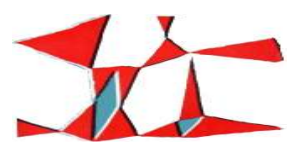

Anuario № 25, Escuela de Historia

Revista Digital № 4, Facultad de Humanidades y Artes, Universidad Nacional de Rosario, 2013

ISSN 1853-8835 